\section{TÀI LIÊU THAM KHẢO}

1. Nguyễn Thị Sen (2015), Thực trạng bệnh sâu răng, nhu cầu điều tri và ành hưởng của bểnh đến chất lượng cuộc sống ở người cao tuổi tỉnh Yên Bái năm 2015. Luận văn thạc sỹ y học, Đại học Y Hà Nôii, 44-57.

2. Nguyễn Thị Châu Thoa, và cs (2012), A Vietnamese version of the 14-item oral health impact profile OHIP-14VN, Journal of Epidemiology, 2, 28-35.

3. Phạm Văn Việt (2004), Nghiên cứu tình trạng, như câu chăm sóc sức khỏe răng miệng và đánh giá kết quả hai năm thực hiện nội dung chăm sóc răng miệng ban đầu ở người cao tuổi tại Hà Nội. Luận án tiến sĩ y học, trường Đai học Y Hà Nội, 64-75.

4. Bernabé E và cs (2010), Periodontal disease and quality of life in British adults, Journal of Clinical Periodontology 37, 968-972.

5. Needleman I và CS (2004), Impact of oral health on the life quality of periodontal patients, Journal of Clinical Periodontology, 31, 454-457.

6. Rodakowska và cs (2014), Quality of life measured by OHIP-14 and GOHAI in elderly people from Bialystok, north-east Poland, BMC Oral Health, 14(106), 1-8.

7. Silva A E R và cs (2013), Oral health-related quality of life and associated factors in Southern Brazilian elderly, Gerodontology, 32, 35-45.

8. Ulinski K B G và cs (2013), Factors Related to Oral Health-Related Quality of Life of Independent Brazilian Elderly, International Journal of Dentistry, 2013, 1-8.

\title{
TÌM HIỂU YẾU Tố NGUY Cơ NHIỄM KHUẨN VẾT Mổ TẠI KHOA NGOẠI BÊ̂NH VIỆN ĐỐNG ĐA, HÀ NộI NĂM 2021
}

\section{Nguyễn Minh Duyên ${ }^{1}$, Lê Thanh Hải ${ }^{1}$, Nguyễn Thị Phương Thùy ${ }^{1}$, Bùi Kim Cương ${ }^{1}$, Lê Thị Thắm ${ }^{1}$, Trần Tuyết Minh ${ }^{1}$}

\section{TÓM TẮT}

Đặt vấn đề: Nhiễm khuẩn vết mổ (NKVM) vẫn là mối lo ngại toàn cầu cần kiểm soát trong số những nhiếm khuẩn bệnh viện phổ biến. Mục tiêu nghiên cứu tìm hiểu các yếu tố nguy cơ liên quan đến NKVM nhằm đưa ra chiến lược kiểm soát phù hợp. Đối tượng và phương pháp nghiên cứu: Tiến cứu mô tả cắt ngang toàn bộ các người bệnh từ trên 8 tuổi, không phân biệt giới được điều trị phẫu thuât thuộc các chuyên khoa: Tiêu hóa -Tiết niêu - Chấn thương. Hồ sơ bệnh án đầy đủ trong thời gian từ tháng 5 đến tháng 9 tại khoa Ngoai bênh viện Đống Đa, Hà Nội. Số liệu được ghi chép hồ sở mẫu, xử lý bằng phần mềm SPSS. 20.0. Kết quả: Tổng số 138 người bênh đat yêu câuu nghiên cứu, nam chiếm $55,1 \%$, nữ chiếm 44,9\%: Yếu tố nguy cơ gồm: Yếu tố người bênh, yếu tố phẫu thuật, yếu tố môi trường và chăm sóc người bệnh. Trong đó yếu tố người bệnh có: tuổi $>60$ tuổi chiếm 36,2\%. Thừa cân, béo phì chiếm 13,8 \%; Yếu tố phẫu thuật: Có vật liệu thay thế + dẫn lưu chiếm $22,5 \%$ và $60,9 \%$. Thời gian phâu thuật dài: từ 60 đến 120 phút chiếm đa số $(76,8 \%), \geq 120$ phút chiếm $18,1 \%$. Yếu tố môi trường và nhân viên y tế: Phòng mố cấp cứu, phòng mổ liên chuyên khoa chưa thực hiện 1 chiều; Bệnh viện chưa có quy định sử dụng kháng sinh dự phòng; $42 \%$ người bệnh không được tắm khử khuẩn trước mổ; $84,8 \%$ người bệnh không được loại bỏ lông tóc theo qui định. Kết luân và khuyến nghị: Qua những yếu tố nguy cơ phát hiện trong nghiên cứu có thể làm tăng tỷ lệ NKVM, chúng

${ }^{1}$ Bệnh viện Đa khoa Đống Đa, Hà Nội

Chịu trách nhiệm chính: Nguyễn Minh Duyên

Email: drminhduyen@gmail.com

Ngày nhận bài: 27.10.2021

Ngày phản biện khoa học: 21.12.2021

Ngày duyệt bài: 30.12.2021 tôi khuyến nghị bệnh viện cân bổ sung một số qui trình và giám sát về an toàn phẫu thuật, các khoa phòng liên quan và nhân viên cần tuân thủ.

Tứ khóa: Nhiễm khuẩn vết mổ; An toàn phẫu thuật; Yếu tố nguy cơ; Chăm sóc vết mổ.

\section{SUMMARY \\ IDENTIFYING THE RISK FACTORS RELATED TO THE SURGICAL SITE INFECTION AMONG THE PATIENTS HAVE BEEN TREATED IN THE SURGICAL DEPARTMENT OF DONGDA GENERAL HOSPITAL, 2021}

Introduction: Surgical Site Infections (SSI) are still a concern globally to control among common nosocomial infections. The aim of the study is to identify the risk factors related in order to make an appropriate control strategy. Materials and methodologies: A cross-sectional descriptive study of all patients from 8 years of age, regardless of gender, who were surgically treated in specialties: Gastroenterology - Urology - Trauma, medical records were completed during the period from May to September at the Department of Surgery, Dong Da Hospital, Hanoi. The data were collected and processed by SPSS software. 20.0. Results: A total of 138 patients met the study requirements, male $55.1 \%$, female $44.9 \%$; Risk factors include: patients surgical procedures- environmental and patient care. In which, patient factors: age > 60 years old accounted for $36.2 \%$. Overweight and obesity accounted for 13.9\%; Surgical procedures: implant materials + drainage accounted for $22.5 \%$ and $60.9 \%$ respectively. Operation duration: from 60 to 120 minutes accounted for the majority,76.8\%, $\geq 120$ minutes accounted for $18.1 \%$. Environmental factors and medical staff: Emergency operating rooms and others have not been set one-way; prophylactic 
antibiotics has been not implemented; $42 \%$ of patients were not given a pre-operative disinfecting bath before operation; hair was not removed properly in accordance with regulation. Conclusions and recommendations: Through the risk factors found in the study that might increase the rate of SSI, we recommend the hospital needs to conduct some procedures and survey the surgical safety program, the departments relevant and medical staff should comply with.

Keywords: Surgical site infection; Surgical safety; Risk factor; Wound care.

\section{I. ĐĂT VẤN ĐỀ}

Nhiễm khuẩn vết mổ (NKVM) là loại nhiễm khuẩn bệnh viện phổ biến, hiện vẫn là mối lo ngại toàn câuu đối với chăm sóc y tế. Chỉ tính riêng tại $M y ̃$, NKVM đứng thứ 2 sau nhiễm khuẩn tiết niệu, chiếm 24,0\% nhiễm khuẩn bệnh viên nói chung và tỷ lệ tử vong khoảng $1,9 \%$. Nhiễm khuẩn vết mổ đang là thách thức lớn đối với hầu hết các bệnh viện trên thế giới đặc biệt là bệnh viện ở các nước đang phát triển. Ở một số bệnh viện khu vực châu Á như Ấn Độ, Thái Lan nhiễm khuẩn liên quan phẫu thuật gặp ở 8,8\% - 24,0\% người bệnh phẫu thuật, trong đó phân lớn là nhiễm khuẩn vết mổ. Không chỉ ảnh hưởng chất lượng chăm sóc, nhiễm khuẩn bệnh viện nói chung, NKBV nói riêng làm tăng gánh nặng chăm sóc y tế do kháng kháng sinh, kéo dài thời gian nằm viện, tăng tỷ lệ mắc $[1,2]$

Theo thống kê của Bộ Y tế tại Việt Nam, trung bình mối năm có khoảng 2 triệu người được phẫu thuật chiếm khoảng 22,3\% trên tổng số hơn 9 triệu người bệnh nhập viện, NKVM chiếm từ $3 \%$ - 10\% trong tổng số người bệnh được phẫu thuật trong một số những nghiên cưuu đa trung tâm gần đây [3]

Bệnh viện Đa khoa Đống Đa là Bênh viện thuộc Sở Y tế Hà nội với quy mô 290 giường bệnh. Trong những năm gân đây mỗi năm bệnh viện phẫu thuật từ 600 đến 700 trường hợp, nhiễm khuẩn bệnh viện nói chung, NKVM nói riêng được quan tâm. Một nghiên cứu cắt ngang 2020 cho thấy tỷ lệ NKBV trên 1,7\%. Mặc dù số liệu cho thấy NKVM không cao, tuy nhiển nhiêu yếu tố nguy cơ liên quan đến NKVM chưa được thống kê đây đủ để có chiến lược lâu dài cho bệnh viện. Do vậy chúng tôi thực hiện đề tài: " Tìm hiểu yếu tố nguy cơ nhiễm khuẩn vết mổ tại bệnh viện Đống Đa, Hà Nội năm 2021".

II. ĐỐI TƯợNG VÀ PHƯƠNG PHÁP NGHIÊN CỨU

Đối tượng nghiên cứu. Toàn bộ người bệnh được điêuu trị phẫu thuật tại khoa Ngoại gồm các chuyên khoa: Tiết niệu- Chấn thương Tiêu hóa, Bệnh viện Đa khoa Đống Đa, không phân biệt giới. Hồ sơ đây đủ thông tin trong thời gian nghiên cứu.

Tiêu chuẩn lựa chọn. Người bệnh từ 8 tuổi trở lên; Người bệnh/gia đình người bệnh đồng ý tham gia vào nghiên cứu

Tiêu chuẩn loại trư. Người bệnh đã được phẫu thuật từ nơi khác chuyển đến; Người bệnh chuyển viện trong quá trình điều trị.

\section{Các biến nghiên cứu}

Yếu tố người bệnh: tuổi, giới, thừa cân BMI (phiên bản 2019 của WHO) với người bệnh trên 18 tuổi, suy giảm miễn dịch, điểm ASA - chỉ số đánh giá nguy cơ phẫu thuật của Hiệp hội gây mê Mỹ - American Society of Anesthesiologists.

Yếu tố môi trương: Yếu tố kỹ thuật và chăm sóc người bệnh

Phương pháp nghiên cứu

Thời gian. Thời gian nghiên cứu từ tháng 05/2021 đến tháng $9 / 2021$

Thiết kế nghiên cứu. Nghiên cứu mô tả cắt ngang

Thiết kế hồ sơ mẫu và tập huấn người giám sát, ghi chép hồ sơ mẫu

Đạo đức nghiên cứu. Đề cương được thông qua Hội đồng khoa học và công nghệ bệnh viện

Phân tích và xử lý số liệu: Phân mêm SPSS. 20.0

III. KẾT QUẢ NGHIÊN CỨU

Bảng 1. Yêu tốngười bệnh

\begin{tabular}{|c|c|c|}
\hline Mô tả & $\begin{array}{l}\text { Tân xuất } \\
(n=138)\end{array}$ & $\begin{array}{l}\text { Tỷ lệ } \\
(\%)\end{array}$ \\
\hline \multicolumn{3}{|c|}{ Nhóm tuối } \\
\hline Từ 8 đến $\leq 18$ tuối & 6 & 4,4 \\
\hline $19-40$ tuối & 27 & 19,6 \\
\hline $41-60$ tuối & 55 & 39,8 \\
\hline$>60$ tuối & 50 & 36,2 \\
\hline \multicolumn{3}{|c|}{ Giới tính } \\
\hline Nam & 76 & 55,1 \\
\hline Nũ̃ & 62 & 44,9 \\
\hline \multicolumn{3}{|c|}{ Tình trạng dinh dưỡng (BMI) } \\
\hline Gây $(<18,5)$ & 10 & 7,2 \\
\hline Bình thường $(18,5-22,9)$ & 109 & 79,0 \\
\hline Thừa cân (23) & 16 & 11,6 \\
\hline Béo phì (> 23) & 3 & 2,2 \\
\hline \multicolumn{3}{|c|}{ Điếm ASA trước phâu thuật } \\
\hline I & 5 & 3,6 \\
\hline II & 130 & 94,2 \\
\hline III & 3 & 2,2 \\
\hline \multicolumn{3}{|c|}{ Người bênh mắc bênh lý kèm theo } \\
\hline Đái tháo đường & 6 & 4,3 \\
\hline Tăng huyết áp & 13 & 9,4 \\
\hline HIV $(+)$ & 7 & 5,1 \\
\hline Khác & 112 & 81,2 \\
\hline
\end{tabular}




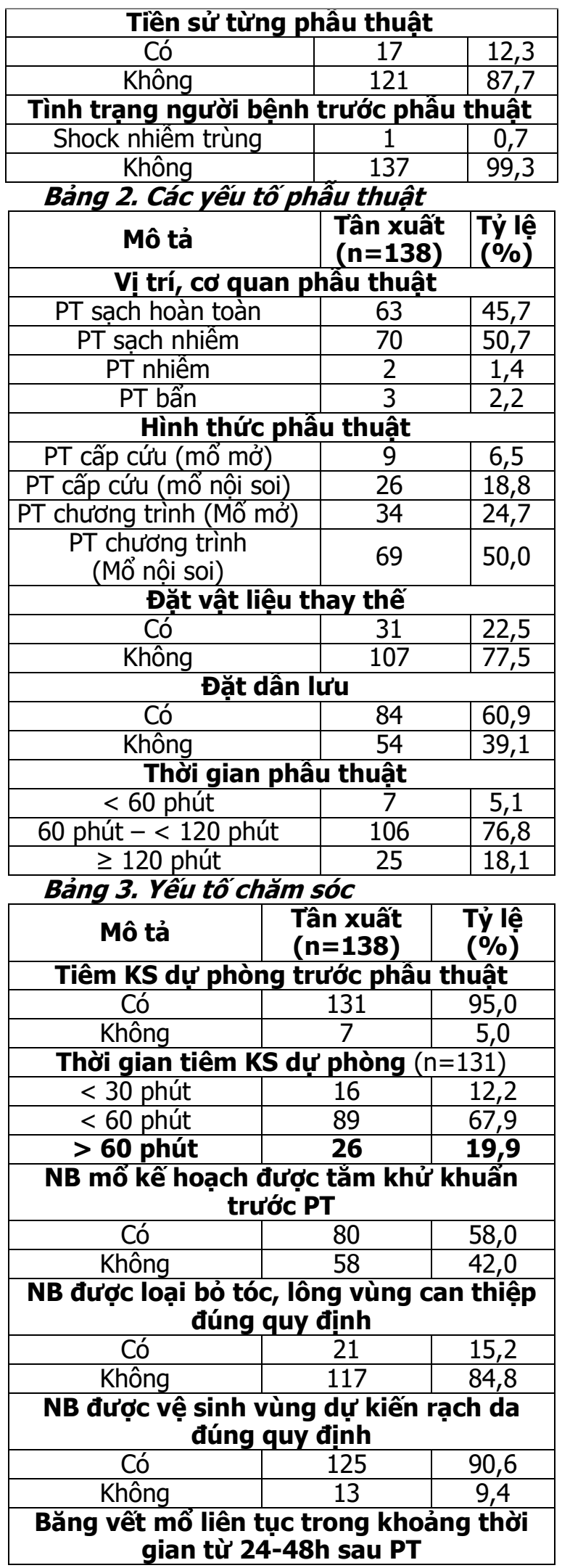

\begin{tabular}{|c|c|c|}
\hline Có & 116 & 84,1 \\
\hline Không & 22 & 15,9 \\
\hline \multicolumn{2}{|c|}{$\begin{array}{c}\text { Thay băng khi băng thấm máu dịch hoặc } \\
\text { khi mờ kiểm tra vết mồ }\end{array}$} \\
\hline Có & 131 & 94,9 \\
\hline Không & 7 & 5,1 \\
\hline
\end{tabular}

\section{BÀN LUÂN}

Những yếu tố của người bệnh đóng vai trò quan trọng đối với tình trạng NKVM bao gồm: lớn tuổi, tình trạng dinh dưỡng (BMI); đang mắc nhiễm khuẩn; đa chấn thương; thời gian nằm viện trước mổ dài; bệnh tiểu đường; ung thư; suy giảm miễn dịch (HIV); tình trạng bệnh nặng trước phẫu thuật $[1,2,4]$.

Trong tổng số 138 người bệnh được nghiên cứu cho thấy tỷ lệ người bệnh trên 60 tuổi chiếm tới 36,2\% (bảng 1). Nghiên cứu của Lê Tuyên Hồng Dương (2012) [5] cho kết quả NKVM cao nhất ở nhóm tuổi trên 76 với tỷ lệ 16,7\%. Nghiên cứu của Nguyễn Thị Mai Thảo (2014) [4] cho thây người bệnh nhóm tuổi $\geq 60$ tuổi có tỷ lệ NKVM là $11,92 \%$ cao hơn tỷ lệ NKVM của người bệnh trong nhóm tuổi < 60 (3\%) có ý nghĩa thống kê.

Các yếu tố nguy cơ khác như thừa cân và béo phì $(13,8 \%)$, bệnh nền như cao huyết áp, tiểu đường..(18,8\%), ASA III $(2,1 \%)$, trong nghiên cứu (bảng 1). Theo Ozgen Isik và cộng sự (2015) [6] béo phì có nguy cơ mắc NKVM cao gấp 3,2 lần so với người bệnh không bị béo phì. Tác giả Nguyễn Quốc Anh (2008) [7] cho thấy nguy cơ NKVM ở những người bệnh có bệnh kèm cao hơn (có ý nghĩa thống kề) so với những người bệnh không có bệnh kèm theo. Ngoài ra trong tổng số 138 người bệnh tham gia vào nghiên cứu, có $12,3 \%$ người bệnh đã phẩu thuật trước đó (bảng 1).

Trong nghiên cứu của Trần Đỗ Hùng và Dương Văn Hoành (2013) [8] tại BV Đa khoa Trung ương Cần thơ cho thấy có mối liên quan giữa NKVM và độ ASA. Nghiên cứu của Nguyễn Thị Mai Thảo (2014) [4] cho thấy nhóm NB có điểm ASA $\geq 3$ có tỳ lệ NKVM là $37,5 \%$ cao hơn nhóm NB có điểm ASA < 3 (3,5\%) có ý nghĩa thống kê.

Các yếu tố nguy cơ trong cuộc mổ như thời gian kéo dài trên 120 phút chiếm 18,1\%, vật liệu cây ghép chiếm $22,5 \%$, dẫn lưu chiếm $60,9 \%$ là những yếu tố nguy cơ cao liên quan NKVM. Dị vật/dẫn lưu chính là một trong các con đường để cho VSV xâm nhập vào cơ thể/cơ quan, tổ chức phẫu thuật gây ra NKVM. Nghiên cứu của Ozgen Isik cho thấy người bệnh có dẫn lưu nguy cơ mắc NKVM cao hơn 10,7 lần so với không dặt 
ống dẫn lưu [6].

Điều trị và chăm sóc người bệnh trước và sau phẫu thuật là những yếu tố vô cùng quan trọng nếu như nhân viên y tế thực hiện không tốt sẽ là nguyên nhân dẫn đến NKVM. Kết quả nghiên cứu cho thấy 93,3\% người bệnh được tiêm kháng sinh trước phẫu thuật, tuy nhiên thời gian tiêm trên 60 phút chiếm tới $20 \%$. Theo khuyến cáo của Tổ chức $Y$ tế Thế giới, kháng sinh dự phòng chỉ áp dụng cho các phấu thuật sạch và phẫu thuật sạch nhiễm. Sử dụng kháng sinh dự phòng đúng cách sẽ có tác dụng làm giảm tỷ lệ NKVM tuy nhiên hiên nay bệnh viện vấn chưa triển khai kháng sinh dự phòng (bảng 3).

Trong nghiên cứu cũng cho thây tới $42 \%$ người bênh không được tắm khử khuẩn trước phẫu thuật. Tỷ lệ người bênh được loai bỏ tóc, lông vùng can thiệp đúng quy định chỉ chiếm $15,2 \%$. Đây cũng là những yếu tố nguy cơ dẫn đến NKVM theo khuyến cáo của Tổ chức $Y$ tế thế giới cũng như các báo cáo quốc tế và được bệnh viện đưa vào qui trình.

\section{KẾT LUÂ̂N}

Nghiên cứu trong thời gian 5 tháng năm 2021 tại bệnh viện Đống Đa cho thấy một số yếu tố nguy cơ có liên quan đến nhiễm khuẩn vết mổ như yếu tố người bệnh: tuổi cao, thừa cân và béo phì; Yếu tố kỹ thuật gồm thời gian phẫu thuật kéo dài, vật liệu thay thế và dẫn lưu; Yếu tố môi trường và chăm sóc gồm chưa thiết kế phòng mổ một chiều, tắm và vệ sinh vùng mố trước phẫu thuật chưa được tuân thủ tốt, chưa có qui định sử dụng kháng sinh dự phòng. Chúng tôi khuyến cáo bệnh viện và các khoa phòng liên quan nhất là khoa ngoại và khoa gây mê hồi sức, cũng như khoa kiểm soát nhiễm khuẩn cần tiến hành giám sát thường xuyên sự tuân thủ của nhân viên y tế nhằm giảm nguy cơ nhiễm khuẩn vết mổ.

\section{TÀI LIỆ THAM KHẢO}

1. Leaper, D. J., Van Goor, H., and Reilly, J. (2004), "Surgical Site Infection - a European perspective of incedence and economic burden", Int Wound J. 1(4), pp. 247-273.

2. Anderson, D. J.'(2011), "Surgical site infection", Infectious Disease Clinics of North America. 25(1), pp. 135-153

3. Phạm Văn Tân (2016), "Nghiên cưuu nhiễm khuẩn vết mổ các phẫu thuật tiêu hóa tại khoa Ngoại Bệnh viện Bạch Mai", Luận án Tiến sỹ. Học viện Quẩn $Y$

4. Nguyển Thị Mai Thảo (2014), "Thực trạng nhiếm khuẩn vết mổ và môt số yếu tố nguy cớ ở người bệnh sau phẫu thuật tại Khoa Ngoại Tổng hợp Bệnh viện Đa khoa Đồng Tháp năm 2014", Luận văn Thạc sỹ Quản lý bệnh viện. Trường Đại học Y tế Công cộng, Hà Nội.

5. Lể Tuyên Hống Dương, Đỗ Ngọc Hiếu, và Lựu Thúy Hiên (2012), "Nghiên cứu tình trạng nhiếm khuân trong các loại phẩu thuất tại Bênh viện Giao thông vận tải Trung ương", Tạp chí Y học thực hành. 841(9), tr. 67-71.

6. Ozgen Isik, Ekrem Kaya, and Pinar Sarkut (2015), "Factors Affecting Surgical Site Infection Rates in Hepatobiliary Surgery", Surg Infect. 16(3), p. 281

7. Nguyển Quốc Anh, Nguyễn Việt Hùng, và Phạm Ngọc Trường (2012), "Nghiên cứu một số yếu tố nguy cơ nhiễm khuân vết mổ tại một số bệh viện", Tạp chí Y học thực hành. 830(7), tr. 28-32

8. Trân Đố Hùng và Dương Văn Hoanh (2013), "Nghiên cứu về tình hình nhiễm khuẩn vết mổ và các yếu tố liên quan ở bệnh nhân sau phẫu thuất tại khoa Ngoại bệnh viện đa khoa trung ương Cần tho", Tap chí y học thực hành. 869(5), tr. 131-134.

\section{ĐÁNH GIÁ KẾT QUẢ CỦA PHÁC ĐỒ NỐI TIẾP TRONG ĐIỀU TRI DIẸT TRỪ HELICOBACTER PYLORI Ở BÊ̂NH NHÂN LOÉT HÀNH TÁ TRÀNG}

\section{TÓM TẮT}

Muc tiêu: Phác đồ nối tiếp trong tiệt trừ Helicobacter pylori (HP) được báo cáo có hiệu quả ở một số nước trên thế giới, chính vì vậy chúng tôi

\footnotetext{
1 Trung tâm tiêu hóa gan mật bệnh viện Bạch mai 2Phòng khám đa khoa

Chịu trách nhiệm chính: Nguyễn Công Long

Email: nguyenconglongbvbm@gmail.com

Ngày nhận bài: 22.10.2021

Ngày phản biên khoa họ: 16.12.2021

Ngày duyệt bài: 28.12.2021
}

\section{Nguyễn Công Long1, Vũ Công Phong}

nghiên cứu tỷ lệ tiệt từ HP bằng phác đồ nối tiếp ở Việt nam. Đối tượng và phương pháp: Trong nghiên cứu chúng tôi tuyển chọn được 51 bệnh nhân loét hành tá tràng có HP dương tính được điều trị phác đồ nối tiếp tiệt trừ HP trong 14 ngày với $40 \mathrm{mg}$ esomeprazole, $1 \mathrm{~g}$ of amoxicillin, hai lần/ngày trong 7 ngày, sau đó 40mg esomeprazol, 500mg clarithromycin, và $500 \mathrm{mg}$ metronidazole, sử dung 2 lần/ ngày trong 7 ngày tiếp theo. Kết quả: Tỷ lệ tiệt từ HP ở phác đồ nối tiếp của chúng tôi đat là $82,4 \%$, và chỉ có chủ yếu là các tác dụng phụ khổng đáng kể là $25,5 \%$ và trong phác đồ nổi tiếp chỉ có một thuốc được thêm vào là metronidazole so với phác đồ chuẩn. Kết luận: Nghiên cứu cho thây rằng phác đồ nối tiếp 